\title{
Survivin-expressing CVD908ssb-TXSVN Vaccine
}

National Cancer Institute

\section{Source}

National Cancer Institute. Survivin-expressing CVD908ssb-TXSVN Vaccine. NCI

Thesaurus. Code C158607.

An orally bioavailable Salmonella-based survivin vaccine composed of a weakened form of a live strain of Salmonella bacteria (CVD908ssb strain) that has been genetically modified to produce the tumor-associated antigen (TAA) survivin, with potential immunopotentiating and antineoplastic activities. Upon administration of the CVD908ssb-TXSVN vaccine, the expressed survivin stimulates the immune response to elicit a cytotoxic $\mathrm{T}$-lymphocyte (CTL)-mediated immune response against survivinexpressing cancer cells, resulting in a decrease in tumor cell proliferation and an induction of tumor cell death. Survivin, a member of the inhibitor of apoptosis (IAP) family expressed during embryonic development, is upregulated in a variety of human cancers while absent in most normal adult cells; its expression in tumors is associated with a more aggressive phenotype, decreased survival, and increased resistance to chemotherapy. 